\title{
Study of spinal anaesthesia with isobaric levobupivacaine and ropivacaine in elective lower limb orthopaedic surgeries
}

\author{
Dinesh Govindarao ${ }^{1}$, Lakshmi Priya ${ }^{2, *}$, Sunitha G. E. ${ }^{3}$ \\ ${ }^{\mathbf{1}}$ Associate Professor, ${ }^{2}$ Assistant Professor, ${ }^{3}$ Resident, Dept. of Anaesthesia, Mysore Medical College and Research Institute, \\ Mysuru, Karnataka, India
}

*Corresponding Author:

Email: c7drpriya@gmail.com

Received: $21^{\text {st }}$ July, 2017

Accepted: $23^{\text {rd }}$ August, 2017

\begin{abstract}
Introduction and Objectives: Levobupivacaine and Ropivacaine, the two S enantiomers of Bupivacaine can be safer alternatives to racemic bupivacaine due to claims of cardiovascular safety profile. Hence, this study was conducted to assess the clinical efficacy of Levobupivacaine and Ropivacaine for spinal anaesthesia for orthopaedic surgeries of lower limbs.

Methods and Materials: For this study, 60 adult ASA class I and II patients admitted for elective lower limb orthopaedic surgeries were randomised to 2 groups of $n=30$ each after approval from ethical committee and informed written consent. Spinal anaesthesia was given with $3 \mathrm{ml}$ Levobupivacaine $0.5 \%(15 \mathrm{mg})$ to patients in Group L and with $3 \mathrm{ml}$ Ropivacaine $0.5 \%(15 \mathrm{mg})$ to patients in Group R. Characteristics of spinal anesthesia in the two subsets like analgesia, motor blockade and hemodynamic parameters were observed and adverse effects, if any, were recorded.

Data obtained were compiled and analysed with suitable statistical tests. A p-value of 0.05 was considered significant.

Results: Onset of sensory and motor block were significantly faster in Group L ( 7 and 1.87 min) compared to Group R ( 9.43 min and $3.10 \mathrm{~min}$ ). The maximum level of analgesia was attained faster in Group L (12.67 mins) compared to Group R (16.67 mins). The two segment regression time and the duration of analgesia were significantly shorter in Group R (72.63 min, $213.93 \mathrm{~min}$ ) compared to Group L (103.6 min, 251.33 mins) Higher grade of motor blockade was achieved rapidly in Group L (9.03 mins) when compared to Group R (12.63 min). The mean duration of motor blockade was prolonged in Group L (263.67 mins) whereas recovery from motor blockade was earlier in Group $\mathrm{R}$ (151.17 mins). Both the groups had stable hemodynamics and adverse effects were not observed in both the groups.

Conclusion: Intrathecal isobaric Levobupivacaine $15 \mathrm{mg}$ and Ropivacaine $15 \mathrm{mg}$ are effective in lower limb orthopaedic surgeries without significant haemodynamic changes. However, Levobupivacaine produced faster onset, prolonged and higher level of sensory block, prolonged motor blockade compared to Ropivacaine.
\end{abstract}

Keywords: Intrathecal Anaesthesia, Levobupivacaine, Ropivacaine, Lower Limb Orthopaedic Surgeries.

\section{Introduction}

Lower limb orthopaedic surgeries are usually done under spinal anaesthesia due to advantages like ease of administration, rapid onset, predictable level of analgesia and pain relief in the immediate postoperative period. ${ }^{1}$ The commonly used local anaesthetic for this purpose, Bupivacaine has the disadvantage of fatal cardiotoxicity due to its $\mathrm{R}(+)$ isomer. $^{2}$ The $\mathrm{S}(-$ )enantiomers of bupivacaine which are devoid of such side effects are expected to have better cardiovascular safety. ${ }^{3}$ Hence, the present study was conducted to evaluate the two S(-) enantiomers, Levobupivacaine $0.5 \%$ and Ropivacaine $0.5 \%$ for intrathecal anaesthesia in orthopaedic surgeries of lower limbs.

\section{Materials and Methods}

60 adult patients (20 to60 years) of either sex, ASA Class I and II, who were posted for elective lower limb orthopaedic surgeries in a tertiary care hospital were enrolled for the study. Ethical committee approval for the study was taken and patients were explained about the nature of the study and their written consent was obtained. The study population was randomly divided by shuffled sealed envelope method into 2 groups with 30 patients in each group $(\mathrm{n}=30)$.

Group L: To receive $3 \mathrm{ml} \quad(15 \mathrm{mg})$ of $0.5 \%$ Levobupivacaine.

Group R: To receive $3 \mathrm{ml}(15 \mathrm{mg})$ of $0.5 \%$ Ropivacaine.

Pregnant females, emergency surgeries, patients with Body Mass Index more than $28 \mathrm{~kg} / \mathrm{m} 2$, patients shorter than $150 \mathrm{~cm}$ or taller than $180 \mathrm{cms}$, patients with known hypersensitivity to study drugs were not included in the study. After pre-anaesthetic checkup, the patients were premedicated with tablet Alprazolam 0.5 $\mathrm{mg}$ hs and fasted for $6 \mathrm{hrs}$ for solid food and $2 \mathrm{hrs}$ for clear fluids. Intravenous access was secured with an 18 gauge cannula and patients were preloaded with Ringer lactate $10 \mathrm{ml}$ per $\mathrm{kg}$ body weight 30 minutes before spinal anaesthesia. ECG, Heart rate, automated non invasive blood pressure (NIBP) and pulse oximetry $(\mathrm{SpO} 2)$ were monitored. With due aseptic care, lumbar puncture was performed at the level of L3-L4 subarachnoid space through a midline approach using 27G Quincke spinal needle and study drug was injected after confirmation of free flow of CSF. The study drugs Levobupivacaine $0.5 \% 3 \mathrm{ml}(15 \mathrm{mg})$ or Ropivacaine $0.5 \% 3 \mathrm{ml}(15 \mathrm{mg})$ were loaded in a $5 \mathrm{ml}$ syringe by the 
senior anaesthesiologist who was not involved in the study. All the subarachnoid blocks were performed by the same anaesthesiologist who was also the observer of the study. Thus double blinding was achieved where both the observer and the participant were blinded to the study drugs. Sensory blockade was tested using pinprick method with a blunt $27 \mathrm{G}$ needle at $1 \mathrm{~min}$ interval for the first $5 \mathrm{~min}$ after the spinal injection, subsequently at 3 min interval in the next half an hour, and every 15 min interval till the completion of surgical procedure and thereafter every half an hour interval until complete recovery. Modified Bromage scale was used to assess quality of motor block (grade 0-no loss of motor power to grade 4 -complete paralysis). Using a pre tested proforma the following parameters were recorded-

1. Onset of sensory blockade to T10 level

2. Onset of motor blockade (Bromage scale 1).

3. Maximum dermatomal level of sensory blockade attained and the time to achieve it.

4. Two segment sensory regression time.

5. Maximum grade of motor blockade attained and the time to achieve it.

6. Total duration of analgesia (time to regression to L1)

7. Duration of motor blockade (regression to Bromage 0).

Total duration of surgery, total duration of post operative analgesia (time to first request for analgesia) and adverse effects if any, were noted. All patients haemodynamic parameters were monitored till complete sensory and motor recovery, employing multiparameter monitor. Hypotension (fall in SBP less than $90 \mathrm{~mm}$ of $\mathrm{Hg}$ or more than $30 \%$ fall in SBP from the baseline value) was treated with rapid IV fluid boluses and if needed inj. Mephenteramine $3 \mathrm{mg}$ IV increments. Bradycardia (heart rate less than $60 \mathrm{bpm}$ ) was treated with injection Atropine0.6mg IV. Patients were also monitored for adverse effects like nausea and vomiting, pruritus and any hypersensitivity reactions for the drug.

The observed values were tabulated and statistical analysis was done.

\section{Statistical Analysis}

All the data were entered into spreadsheet and analyzed using Statistical Package for Social Science (SPSS) Windows (Version 22). Descriptive statistical methods were used to summarize the data. Student's ttest was used for continuous variables and Chi-square test was used for categorical data. Statistical significance was considered to be present if $\mathrm{p}$ value was less than 0.05 .

\section{Results}

The two groups were matched in terms of their demographic profiles and the type of surgeries. Time to achieve T10 dermatomal level of analgesia was delayed in Group R (9.43 \pm 2.18 mins) when compared to Group L (7 \pm 4.69 mins $)(p=0.014)$. Level above T6 was attained in 21 cases in Group $\mathrm{L}$ and in 12 members in Group $\mathrm{R}(\mathrm{p}=0.01)$. In nine patients in Group L, it reached $\mathrm{T} 4$ level, whereas only one patient had T4 level in Group $\mathrm{R}(\mathrm{p}=0.000)$. The mean level of sensory block attained was T6 in Group L and T8 in Group R. The maximum sensory blockade was quicker in Group L (12.67 \pm 5.31 mins) compared to Group R (16.67 \pm 4.71 mins) $(\mathrm{p}=0.003)$. The time for two segment regression of sensory block and the duration of analgesia was prolonged in Group L (103.6 \pm 8.37 mins, 251.33 \pm 32.08 mins) compared to Group R (72.63 \pm 10.54 mins, 213.93 \pm 26.65 mins $)(\mathrm{p}=0.000)$.

The onset of motor block was significantly faster in Group L (1.87 \pm 1.94 mins) compared to Group R (3.10 \pm 1.49 mins $) \quad(\mathrm{p}=0.008)$. Complete motor block (Bromage 4) was attained in 25 patients in Group L whereas it was attained only in 16 patients in Group $R$ $(p=0.025)$. Bromage scale 4 level of motor block was achieved significantly slowly in Group R (12.63 \pm 3.5 mins) compared to Group L $(9.03 \pm 2.67$ mins $)$ $(\mathrm{p}=0.000)$. Also, patients in Group $\mathrm{R}$ had a faster recovery of motor power $(151.17 \pm 28.59$ mins $)$ compared to those in Group L (263.67 $\pm 33.61 \mathrm{mins})$ $(\mathrm{p}=0.000)$.

Haemodynamic variables monitored in both the groups (heart rate, systolic, diastolic and mean blood pressures) at various time intervals did not show any significant variation.

There was no observed incidence of shivering, headache, nausea, vomiting and Oxygen desaturation (SpO2 93\%) in any patient in both the study groups.

Table 1: Characteristics of spinal anaesthesia

\begin{tabular}{|l|c|c|c|}
\hline \multicolumn{1}{|c|}{ Parameters } & Group L & Group R & P Value \\
\hline Mean duration of surgery (min) & $80.17 \pm 14.77$ & $75.40 \pm 16.96$ & $\begin{array}{c}0.250 \\
\text { (NS) }\end{array}$ \\
\hline $\begin{array}{l}\text { Mean time of onset of sensory } \\
\text { analgesia at T 10 (min) }\end{array}$ & $7 \pm 4.69$ & $9.43 \pm 2.18$ & $0.014(\mathrm{~S})$ \\
\hline $\begin{array}{l}\text { Mean time to achieve maximum level } \\
\text { of sensory block (min) }\end{array}$ & $12.67 \pm 5.31$ & $16.67 \pm 4.71$ & $0.003(\mathrm{~S})$ \\
\hline $\begin{array}{l}\text { Maximum level of sensory blockade } \\
\text { (dermatomal level) }\end{array}$ & $\mathrm{T} 6$ & $\mathrm{~T} 8$ & - \\
\hline Mean time for two segment sensory & $103.6 \pm 8.37$ & $72.63 \pm 10.54$ & $0.00(\mathrm{~S})$ \\
\hline
\end{tabular}




\begin{tabular}{|l|c|c|c|}
\hline regression (min) & & & \\
\hline $\begin{array}{l}\text { Mean total duration of sensory } \\
\text { blockade (min) }\end{array}$ & $251.33 \pm 32.08$ & $213.93 \pm 26.65$ & $0.000(\mathrm{~S})$ \\
\hline $\begin{array}{l}\text { Mean time of onset of Gr. I motor } \\
\text { block (min) }\end{array}$ & $1.87 \pm 1.94$ & $3.10 \pm 1.49$ & $0.008(\mathrm{~S})$ \\
\hline $\begin{array}{l}\text { Mean time of onset for max. Motor } \\
\text { blockade (min) }\end{array}$ & $9.033 \pm 02.67$ & $12.63 \pm 3.5$ & $0.000(\mathrm{~S})$ \\
\hline $\begin{array}{l}\text { Mean number of patients with Gr.4 } \\
\text { Motor blockade (\%) }\end{array}$ & $83.3 \%$ & $53.3 \%$ & $0.025(\mathrm{~S})$ \\
\hline $\begin{array}{l}\text { Mean total duration of Motor } \\
\text { blockade (min) }\end{array}$ & $263.67 \pm 33.61$ & $151.17 \pm 28.59$ & $0.000(\mathrm{~S})$ \\
\hline
\end{tabular}

Table 2: Adverse Effects

\begin{tabular}{|l|c|c|}
\hline \multicolumn{1}{|c|}{ Parameters } & Group L & Group R \\
\hline Hypotension & 1 (patient) & - \\
\hline Bradycardia & 2 (patients) & 1 (patient) \\
\hline Shivering & - & - \\
\hline $\begin{array}{l}\text { Others(nausea, vomiting, } \\
\text { headache) }\end{array}$ & - & - \\
\hline
\end{tabular}

Table 3: Demographic Data

\begin{tabular}{|l|c|c|c|}
\hline \multicolumn{1}{|c|}{ Parameters } & Group L & Group R & P Value \\
\hline Mean Height $(\mathrm{cm})$ & $158.37 \pm 4.73$ & $157.63 \pm 4.76$ & $0.552(\mathrm{NS})$ \\
\hline Mean Weight $(\mathrm{kg})$ & $58.07 \pm 4.41$ & $56.07 \pm 7.04$ & $0.193(\mathrm{NS})$ \\
\hline
\end{tabular}

\section{Discussion}

The $\mathrm{S}$ enantiomeres of Bupivacaine are said to be nearly identical to it in the onset, quality and duration of sensory block but having a better safety profile. ${ }^{3}$ As they cause less depression of myocardial contractility, the cardiotoxicity of Levobupivacaine and Ropivacaine is less than racemic Bupivacaine. There are claims that Levobupivacaine is equipotent and Ropivacaine $2 / 3 \mathrm{rd}$ as potent as racemic Bupivacaine. ${ }^{4,5}$ Isobaric local anaesthetics appear ideal for surgeries below T10 dermatomal level. The extent of intrathecal anaesthesia is dependent on local anaesthetic dose rather than it's volume. ${ }^{6,7}$ For spinal anaesthesia for hip replacement surgery, Glaser C suggested a dose of $17.5 \mathrm{mg}(3.5 \mathrm{~mL}$, $0.5 \%$ ) of isobaric Levobupivacaine. ${ }^{8}$ The mass of isobaric Ropivacaine suggested for intrathecal dose varies from 17.5-25 mg. ${ }^{9,10}$ However, for hip replacement surgery, the MLAD of isobaric Levobupivacaine $(11.7 \mathrm{mg})$ and that of Ropivacaine $(12.8 \mathrm{mg})$ as assessed by the up and down method of Dixon are almost similar. ${ }^{11 .}$ These doses are actually ED95 of these drugs and to complete surgery, 15.2 \pm $4.0 \mathrm{mg}$ (mean $\pm \mathrm{SD})$ of Levobupivacaine was required and $15.5 \pm 3.1 \mathrm{mg}$ dose of Ropivacaine was needed. ${ }^{11}$

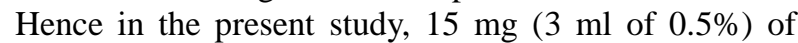
these two drugs were used for lower limb orthopaedic surgeries.

The present study demonstrates the onset of sensory block was faster with levobupivacaine $(7 \pm 4.69$ min) compared to Ropivacaine $(9.43 \pm 2.18 \mathrm{~min})$. This correlates well with the findings of 7(3-19) min by Sen $\mathrm{H}^{12}$ and $6.6 \pm 4.7$ mins by Sanansilp $\mathrm{V}^{13}$ for
Levobupivacaine and the observations of Casati ${ }^{14}(10 \pm 5$ $\mathrm{min})$ and that of Kallio $\mathrm{H}^{5}(10 \mathrm{~min})$ for Ropivacaine. Mantouvalou ${ }^{15}$ observed delayed onset times for both drugs ( $11 \pm 6$ min for Levobupivacaine and $12 \pm 7 \mathrm{~min}$ for Ropivacaine) probably due to the higher dermatomal level (T8) taken as reference level in their study. But they also observed faster onset of sensory block with Levobupivacaine, as in the present study.

In the present study, median dermatomal analgesia level was T6 with Levobupivacaine and T8 with Ropivacaine $(\mathrm{p}=0.01)$. This level of sensory block with Ropivacaine is consistent with those reported by Fettes, ${ }^{16}$ Mantouvalou M, ${ }^{15}$ Malinovsky ${ }^{17}$ and Kallio. ${ }^{5}$

The highest level of analgesia was T4 (n=9) in Levobupivacaine group which is comparable to the studies by Guler G. ${ }^{18}$ However, the difference in the maximum level of analgesia obtained by Casati ${ }^{14}$ (T8) and Sanansilp V ${ }^{13}$ (T8) and M Del-Rio- Vellosillo ${ }^{19}$ (T6) may be due to the smaller dose of Levobupivacaine used by them $(8 \mathrm{mg}, 12.6 \mathrm{mg}$ and $12.5 \mathrm{mg}$ respectively). Highest dermatomal block level with $0.5 \%$ Ropivacaine reported by Van Kleef ${ }^{20}$ of T11 is at variance with our findings of T4 $(n=1), T 6(n=9)$. This may be explained by the variation in the mean height of the study population- $177 \mathrm{cms}$ and $157.63 \mathrm{~cm}$ in van Kleef ${ }^{20}$ and in our study respectively.

The earlier onset of maximum dermatomal block level with Levobupivacaine $(12.67 \pm 5.31 \mathrm{~min})$ compared to Ropivacaine $(16.67+4.71 \mathrm{~min})$ in the present study is consistent with those obtained by Sanansilp $\mathrm{V}^{13}$ $(13.8 \pm 6.8 \mathrm{~min})$ and Guler $\mathrm{G}^{18}(11.96 \pm 1.97 \mathrm{~min})$ for Levobupivacaine and also with the values obtained by 
by van Kleef ${ }^{20}$ (15 mins) and Mantouvalou $\mathrm{M}^{15}(12 \pm 7$ mins) for Ropivacaine. However, using a higher mass of drug ( $3.5 \mathrm{ml}$ of $0.5 \%$ Levobupivacaine), Glaser $\mathrm{C}^{8}$ in his studies reported a more rapid onset time of 8-10 min for maximum level of sensory blockade to $\mathrm{T} 8$ which is at variance from our results.

With Ropivacaine $0.5 \%$, Wahedi ${ }^{21}$ reported the time for maximum sensory block as 24 min which is differing from many studies including our study. This is probably due to the difference in the assessment of the sensory level i.e loss of perception of cold sensation in their study and pin prick method in our study. The temperature sensation is carried through nonmyelinated $\mathrm{C}$ fibers resistant to the blocking effects of local anaesthetics in vivo. ${ }^{1}$

With Levobupivacaine, the two segment sensory regression time $(103.6 \pm 8.37 \mathrm{~min})$ and the duration of analgesia $(251.33+32.08$ mins $)$ were prolonged compared to Ropivacaine $(72.63 \pm 10.54 \mathrm{~min}$ and $213.93 \pm 26.65 \mathrm{~min})$ consistent with the results of Mantouvalou $\mathrm{M}^{15}$ and Sanansilp V ${ }^{13}(98.3 \pm 29.5 \mathrm{~min})$ Kallio, ${ }^{5}$ Del-Rio-Vellosillo M. ${ }^{19}$

However, Glaser $\mathrm{C}^{8}$ had obtained a higher two segment regression $(152 \pm 48 \quad \mathrm{~min})$ with Levobupivacaine, probably because of the higher mass of the drug used (3.5 $\mathrm{ml} 0.5 \%$ Levobupivacaine). With the use of $10 \mathrm{mg}$ of $0.5 \%$ Levobupivacaine and $15 \mathrm{mcg}$ of Fentanyl, Guler $\mathrm{G}^{18}$ reported a two segment sensory regression time of $71.43 \pm 12.96 \mathrm{~min}$ which is well below our values.

The duration of analgesia with Levobupivacaine obtained in our study correlates well with those of Glaser $\mathrm{C}^{8}$ and Del-Rio-Vellosillo M. ${ }^{19}$ However the duration of sensory blockade by Levobupivacaine shows wide variation in studies by various investigators; $391 \pm 96$ min with Fattorini $\mathrm{F}^{22}$ to 100 (34-180) min with Sen H. ${ }^{11}$ This may be explained by the drug's isobaric nature as suggested by Sanansilp V. ${ }^{13}$

With $0.5 \%$ Ropivacaine, longer duration of analgesia was reported by Van Kleef ${ }^{20}$ and Fettes ${ }^{16}$ (268 min and $270 \mathrm{~min}$ respectively) which are at variance from our observations. This is because they have taken the time for complete sensory regression (at S2) unlike the time taken for the first request for rescue analgesia as done in our study.

The onset of motor blockade was faster with Levobupivacaine $(1.87 \pm 1.94 \mathrm{mins})$ compared to Ropivacaine $(3.10 \pm 1.49$ mins) and is consistent with the results by Mantouvalou et al. ${ }^{15}$ (Levobupivacaine 2 $\pm 1 \mathrm{~min}$ and Ropivacaine $3 \pm 1 \mathrm{~min}$ ).

In our study, we found that patients given Levobupivacaine had more intense motor blockade Bromage grade 4 and achieved it earlier than those given Ropivacaine $(83.3 \%$ vs $53.3 \%$ patients, $9.03 \pm 2.67 \mathrm{~min}$ vs. $12.63 \pm 3.5 \mathrm{~min}$ ) respectively. While all 30 patients given Levobupivacaine had Bromage 3 and 4 motor blockade, only 29 patients given Ropivacaine had Bromage 3 and 4 and one patient did not progress beyond Bromage 2. Results are comparable to Mantouvalou ${ }^{15}$ and Guler $G^{18}(11.36 \pm 2.35)$. Sanansilp $\mathrm{V}^{13}$ who used lower mass of isobaric Levobupivacaine had slight delay in maximum motor blockade $(13.6 \pm 7.3$ min). The delay in obtaining maximum motor blockade by Van Kleef ${ }^{20}$ in comparison to our study with Ropivacaine $0.5 \%$ (21 $\mathrm{min}$ vs $12.63 \mathrm{~min}$ ) is probably explained by the difference in the mean height of the patients in the two studies $(177 \mathrm{cms}$ vs $157.63 \mathrm{cms}$ respectively).

Prolonged motor blockade was also observed with Levobupivacaine $(263.67 \pm 33.61 \mathrm{mins})$ compared to Ropivacaine $(151.17 \pm 28.59 \mathrm{~min})$ correlating well with Mantouvalou $^{15}$ (351 $\mathrm{min}$ and $249 \mathrm{~min}$ ) respectively. Fattorini $\mathrm{F}^{22}$ and Glaser $\mathrm{C}^{8}$ also reported similar prolonged duration with Levobupivacaine $(256 \pm 86 \mathrm{~min}$, $280 \pm 84 \mathrm{~min}$ ) respectively.

The duration of Ropivacaine induced motor block in our study correlates well with studies by van Kleef, ${ }^{20}$ Wahedi, ${ }^{21}$ Malinovsky, ${ }^{17}$ Kallio $^{5}$ and Fettes ${ }^{16}$ (178 min, $160 \mathrm{~min}, 165 \mathrm{~min}, 150 \mathrm{~min}, 180 \mathrm{~min}$ ) respectively.

Study population in both groups exhibited stable hemodynamics. This was probably due to preloading with Ringer's lactate and application of lower limb tourniquet in all patients. Our findings correlate with results of Mantouvalou ${ }^{15}$ and Casati A. ${ }^{14}$

\section{Conclusion}

Isobaric $0.5 \%$ Levobupivacaine $(15 \mathrm{mg})$ produced rapid onset, prolonged and higher dermatomal level of analgesia, prolonged and higher grade of motor blockade compared to $0.5 \%$ isobaric Ropivacaine (15 $\mathrm{mg}$ ) in adult patients undergoing elective lower limb surgeries without any significant haemodynamic changes.

\section{References}

1. Cousins MJ. Neural blockade in clinical anaesthesia and pain medicine. 4th ed. Philadelphia: Lippincott Williams and Wilkins;2009.

2. Hansen TG. Ropivacaine: A pharmacological review. Expert Rev Neurother. 2004;4:781-91.

3. McConachie I, McGeachie J, Barrie J. Regional anaesthetic techniques. In: Thomas EJ, Knight PR, eds., Wylie and Churchill Davidson's - A Practice of Anesthesia London: Arnold 2003;37:599-612.

4. Kuthiala G, Chaudhary G. Ropivacaine: A review of its pharmacology and clinical use. Indian J Anaesth 2011;55:104-10.

5. Kallio H, Snall EV, Kero MP, Rosenberg PH. A comparison of intrathecal plain solutions containing Ropivacaine 20 or $15 \mathrm{mg}$ versus bupivacaine $10 \mathrm{mg}$. Anesth Analg 2004;99:713-8.

6. Ben-David B, Levin H, Solomon E, Admoni H, Vaida S Spinal bupivacaine in Ambulatory surgery: the effect of saline dilution. Anesth Analg 1996;83:716-20.

7. Kuusniemi KS, Pihlajamaki KK, Pitkanen MT, Korkeila JE. Low-dose bupivacaine: a comparison of hypobaric and near isobaric solutions for arthroscopic surgery of the knee. Anaesthesia 1999;54:540-5 
8. Glaser C, Marhofer P, Zimpfer G. Levobupivacine versus racemic bupivacaine for spinal anesthesia. Anesth Analg, 2002 94:194-8.

9. McNamee DA, Parks L, McClelland AM. Intrathecal ropivacaine for total hip arthroplasty: double-blind comparative study with isobaric $7.5 \mathrm{mg} / \mathrm{ml}$ and $10 \mathrm{mg} / \mathrm{ml}$ solutions. Br J Anaesth 2001;87:743-7.

10. McNamee DA, McClelland AM, Scott S, Milligan KR, Westman L, Gustafsson U. Spinal anaesthesia: comparison of plain ropivacaine $5 \mathrm{mg} / \mathrm{ml}$ with bupivacaine $5 \mathrm{mg} / \mathrm{ml}$ for major orthopaedic surgery. $\mathrm{Br} \mathrm{J}$ Anaesth 2002;89:702-6.

11. Sell A, Olkkola KT, Jalonen J, Aantaa R. Minimum effective local anaesthetic dose of isobaric Levobupivacaine and Ropivacaine administered via a spinal catheter for hip replacement surgery. Br J Anaesth 2005;94(2):239-42.24.

12. Sen H, Purtuloglu T, Sizlan A, Yanarates O, Ates F, Gundu I, et al. Comparison of intrathecal hyperbaric and isobaric levobupivacaine in urological surgery. Minerva Anesthesiol 2010;76:24-8.

13. Sanansilp V, Trivate T, Chompubai P, Visalyaputra S, Suksopee P, Permpolprasert L, et al. Clinical characteristics of spinal levobupivacaine: hyperbaric compared with isobaric solution. Scientific World Journal 2012;2012:169076.

14. Casati A, Moizo E, Marchetti C, et al. 2004a. A prospective, randomized, doubleblind comparison of unilateral spinal anesthesia with hyperbaric bupivacaine, ropivacaine, or levobupivacaine for inguinal herniorrhaphy. Anesth Analg 99:1387-92.

15. Mantouvalou M, Ralli S, Arnaoutoglou H, Tziris G, Papadopoulos G. Spinal anaesthesia: Comparison of plain Ropivacaine, Bupivacaine and Levobupivacaine for lower abdominal surgery. Acta Anaesth Belg 2008;59:65-71.

16. Fettes W, Hocking G, Peterson M, Luck JF, Wildsmith AW. Comparison of plain and hyperbaric solutions of Ropivacaine for spinal anaesthesia. Br J Anaesth 2005;94:107-11.

17. Malinovsky JM, Charles F, Kick O, Lepage JY, Malinge M, Cozian A, et al. Intrathecal anaesthesia: Ropivacaine versus bupivacaine. Anesth Analg 2000;91:1457-60.

18. Guler G, Cakir G, Ulgey A, Ugur F, Bicer C, Gunes I et al. A Comparison of Spinal Anesthesia with Levobupivacaine and Hyperbari Bupivacaine for Cesarean Sections: A Randomized Trial. Open Journal of Anesthesiology 2012;2(3):84-9.

19. Del-Rio-Vellosillo M, Garcia-Medina JJ, AbengocheaCotaina A. Doses and effects of levobupivacaine and bupivacaine for spinal anaesthesia. British Journal of Anaesthesia 2014;113(3):521-2.

20. Van Kleef JW, Veering BT, Burm AGL. Spinal anaesthesia with Ropivacaine: a double blind study on the efficacy and safety of $0.5 \%$ and $0.75 \%$ solutions in patients undergoing minor lower limb surgery. Anesth Analg 1994;78:1125-30.

21. Wahedi W, Nolte H, Klein P. Ropivacain zur spinalana"sthesie. Eine dosisfindungsstudie. Anaesthesist 1996.

22. Fattorini F, Ricci Z, Rocco A. Levobupivacaine versus racemic bupivacaine for spinal anaesthesia in orthopaedic major surgery. Minerva Anestesiol 2006;72:637-44. 